\title{
Agricultural production and malaria resurgence in Central America and India
}

\section{Georganne Chapin* \& Robert Wasserstrom $†$}

AMONG the inhabitants of Asia, Latin America and tropical Africa malaria remains a major cause for alarm. Yet only a few years ago, health officials in a dozen developing countries (capitalizing on the discoveries of British parasitologist Ronald Ross half a century earlier) pointed triumphantly at their efforts to eradicate entirely this mosquito-borne scourge ${ }^{1-5}$. Following World Health Organization (WHO) guidelines, for example, Indian authorities instituted a programme of medical treatment and pesticide application in 1952 which within a single decade reduced the number of cases from over 100 million to 50,000 (ref. 6). Ten years later, using the same methods, health workers in Sri Lanka cut the annual incidence of malaria from three million cases to fewer than 25 .

By 1970, however, it had become clear which mosquitoes of the Anopheles subfamily transmit Plasmodium parasites to human beings. After reproducing in astronomical numbers, these parasites transform their human hosts into a reservoir of illness which may be spread to uninfected individuals.

In 1907, Dr William Gorgas, an American Army surgeon in the Panama Canal Zone, set out to break this cycle by draining swamps, emptying, covering or oiling pools of standing water and screening human habitations. Although he was unable to eradicate the disease completely, within two years the death rate from malaria among canal company employees had fallen to 8.86 per thousand - a decrease of 80 per cent. More or less simultaneously an Italian physician, Dr Angelo Celli, noticed that in southern Europe the disease tended to attack people

A few years ago the battle against malaria seemed to have been won. However now, despite vigorous anti-malaria campaigns, the disease has made a comeback. The resurgence of malaria in Central America and India seems to have been paralleled by intensified agriculture in these countries and the associated increased use of pesticides.

that malaria eradication had run into severe difficulties. Instead of dwindling to insignificance, the number of infected individuals rose again to distressing proportions. In India, which had served as a showplace for WHO policies, five million people were soon infected; in Sri Lanka, two million people became sick again almost overnight; and in Central America infection rates grew to previously unknown levels ${ }^{7}$. Moreover, unlike earlier outbreaks, this new plague was often carried by mosquitoes which had become resistant to pesticides like DDT and dieldrin and could not be controlled by conventional means ${ }^{8-15}$. The origins of this major ecological disaster must be sought as much in the unwitting actions of international organizations as in hapless nature.

\section{A seeming success}

It is worth noting that early programmes to contain parasitic diseases - primarily malaria and yellow fever - achieved remarkable success without recourse to sophisticated technologies ${ }^{16}$. Efforts to overcome malaria before the Second World War concentrated on the ways in

*Division of Sociomedical Sciences, School of Public Health, Columbia University, New York, New York 10032, USA.

†Department of Anthropology, and Division of Sociomedical Sciences, Columbia University, New York, New York 10027, USA.

\section{Country}

Costa Rica El Salvador Guatemala Honduras Nicaragua
Source: WHO, World Health Statistics Annual, Geneva, 1966- 79. for a short time on the inside walls of human houses after biting their victims. By spraying walls with DDT, WHO officials reasoned they could reduce the vector population to manageable levels. Simultaneously, they proposed to treat everyone affected by the disease with chloroquine or other anti-Plasmodium drugs so as to destroy the reservoir of disease. If these conditions could be maintained for three or four years, they calculated, malaria transmission might be broken forever. Moreover, projects of this sort could be carried out without altering political arrangements or patterns of land tenure.

\section{Complications}

Despite the simplicity of the plan, WHO officials were aware that a worldwide campaign to eradicate malaria would face nearly insurmountable obstacles. In many regions, control programmes were virtually non-existent, and even those that did exist suffered from a lack of funds, technical expertise and administrative efficiency. But there was another obstacle which experts at WHO were more reluctant to engage: as early as 1953 , they obtained conclusive evidence that Anopheles mosquitoes, like many insect pests, sooner or later became resistant to DDT and other pesticides. Within a few years, in fact, such resistance had been reported in Greece and Italy (where insecticides were used both in public health and in agriculture) as well as in the Lebanon, Iran, Saudi Arabia and Nigeria. In some cases a single application was sufficient to reduce mortality (that is, increase resistance) among mosquitoes by 80 per cent ${ }^{18}$. Accordingly, WHO malariologists urged their local counterparts to conduct "time-limited" spraying operations - to complete the "attack" phase as quickly as possible.

Thus, anti-malaria teams were directed to treat the interior walls of all human habitations and shelters within the target zone on a regular schedule - a gargantuan task under the best of circumstances. Meanwhile, by organizing an elaborate

Table 1 Prevalence of malaria in Central America, 1965-1977

No. of cases (thousands)

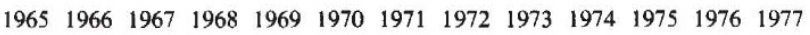

$\begin{array}{lllll}0.6 & 0.3 & 0.3 & 0.2 & 0.2\end{array}$ $\begin{array}{lllllllllllll}34.2 & 68.6 & 83.0 & 35.8 & 25.3 & 45.4 & 46.8 & 38.3 & 35.1 & 67.0 & 83.1 & 83.3 & 32.2\end{array}$ $\begin{array}{lllllllllll}14.3 & 22.0 & 21.2 & 11.0 & 10.6 & 10.9 & 8.3 & 9.3 & 1.0 & 1.0 & 9.6\end{array}$ $\begin{array}{lllllllllllll}6.9 & 17.1 & 16.1 & 15.7 & 29.6 & 34.5 & 48.4 & 18.6 & 8.8 & 7.5 & 30.3 & 48.8 & 39.4\end{array}$ $\begin{array}{llllllllllll}8.3 & 15.6 & 7.1 & 16.0 & 28.5 & 23.3 & 9.6 & 4.2 & 12.2 & 24.7 & 26.2 & 11.6\end{array}$ 
system of regional laboratories and clinics, public health officials were supposed to administer chemotherapy and monitor the campaign's progress. In areas where these tactics proved to be successful, where the number of active cases diminished to zero, attack gave way to consolidation. And if no new illness occurred during the following three years, consolidation was in turn replaced by maintenance, the constant vigil against a recurrence of infection. This strategy was adopted in 1954 by the Pan American Health Organization (PAHO) and subsequently by the entire international community.

Initially, at least, it seemed that WHO's campaign enjoyed almost unmitigated success. In India, after ten years of struggle against malaria (1961), only 50,000 cases of the disease were uncovered by government inspectors and a number of regions had passed from attack to consolidation or maintenance. Similar triumphs were registered in Pakistan, Sri Lanka, Paraguay, Venezuela, Mexico and Central America. In ten other countries, Plasmodium infection was completely overcome.

\section{Malaria re-emerges}

Within a short time, however, the campaign began to falter. Between 1961 and 1966, disease rates in India increased threefold; by 1970 , half a million people caught malaria each year - many in areas where health authorities had recently scored impressive victories. Much the same course of events took place in Sri Lanka, which in 1968 experienced an epidemic that left 1.5 million people stricken. On the other side of the world, in El Salvador, Nicaragua and Honduras (where antimalaria measures began in the late 1960s), the incidence of disease in 1975 was three times greater than a decade earlier, before the programme had started (Table 1). As a result, eradication projects which had reached consolidation frequently reverted to the attack phase - or even entered the newly defined stage of " "permanent attack'. Even so, it soon became clear that there was a major resurgence of malaria in India and Central America that existing administrative and technological methods could do little to prevent ${ }^{19-24}$. The question which malariologists in these areas then asked themselves was quite simply, "What has gone wrong?'”.

In fact, as early as 1962 a number of specialists had expressed their reservations about the WHO campaign and its chances of success. Among other things, they pointed out that as infection rates dropped during the attack phase, hard-pressed governments often diverted critical resources from anti-malaria activities to other essential projects ${ }^{25,26}$. As a result, many infected people were not detected by surveillance systems, which themselves broke down under poor management and supervision. Even more ominously, however, resistance to DDT and dieldrin

Table 2 Land tenure in India, 1970

\begin{tabular}{|c|c|c|c|c|}
\hline $\begin{array}{l}\text { Size of holding } \\
\text { (hectares) }\end{array}$ & $\begin{array}{l}\text { No. of holdings } \\
\text { (thousands) }\end{array}$ & $\begin{array}{l}\% \text { Of rural } \\
\text { properties }\end{array}$ & $\begin{array}{c}\text { Area } \\
\text { (millions of } \\
\text { hectares) }\end{array}$ & $\%$ Of total area \\
\hline$<0.5$ & 23,178 & 32.9 & 5.4 & 3.4 \\
\hline $0.5-1.0$ & 12,504 & 17.7 & 9.1 & 5.6 \\
\hline $1.0-1.9$ & 13,432 & 19.1 & 19.3 & 11.9 \\
\hline $2.0-2.9$ & 6,722 & 9.5 & 16.4 & 10.0 \\
\hline $3.0-3.9$ & 3,959 & 5.6 & 13.6 & 8.4 \\
\hline $4.0-4.9$ & 2,684 & 3.8 & 11.9 & 7.4 \\
\hline $5.0-9.9$ & 5,248 & 7.4 & 36.3 & 22.4 \\
\hline $10.0-19.9$ & 2,135 & 3.0 & 28.5 & 27.6 \\
\hline $20.0-29.9$ & 401 & 0.6 & 9.3 & 5.8 \\
\hline $30.0-39.9$ & 120 & 0.2 & 4.2 & 2.6 \\
\hline $40.0-49.9$ & 45 & 0.1 & 2.1 & 1.3 \\
\hline$>50$ & 65 & 0.1 & 6.0 & 3.1 \\
\hline Total & 70,493 & 100.0 & 162.1 & 100.0 \\
\hline
\end{tabular}

Source: Ministry of Planning, Government of India, Statistical Abstract, India, 1977, New Delhi, 1978.

had reached alarming proportions among Anopheles mosquitoes - just as WHO officials had originally feared ${ }^{27,28}$.

The case of El Salvador is illuminating. In 1958 a group of entomologists reported that the local vector, Anopheles albimanus, had lost its susceptibility to all major organochlorine compounds and was proliferating rapidly along the Pacific coast $^{29,30}$. Four years later, researchers in southern Mexico encountered the same problem, which forced them to admit that the disease had not been eradicated in several areas ${ }^{31}$. In India, widespread tolerance to organochlorines was discovered among two important vectors, Anopheles culifacies and Anopheles fluviatilis, particularly in regions which had recently shifted to high-yielding forms of agricultural production ${ }^{32}$.

In such places, effective control might be regained only by using insecticides which cost four, five or even ten times as much as common toxins - a burden which few governments were willing to bear ${ }^{33}$. Yet

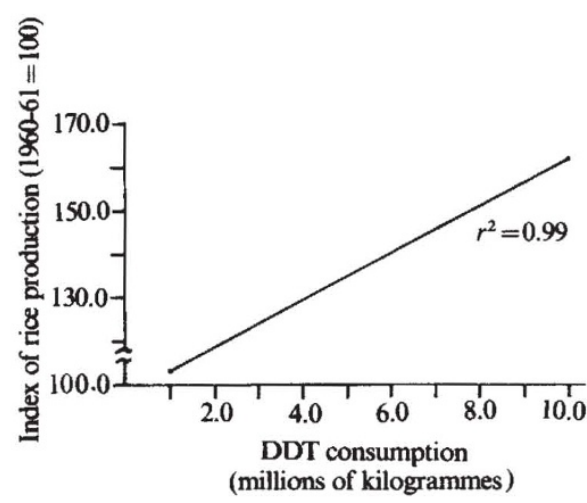

Fig.1 Effect of DDT use on rice production in India, 1970-77 even measures of this kind might serve at best only as temporary expedients: vectors which became resistant to one compound frequently enjoyed mysterious immunity to other unrelated poisons, and in any case it was only a matter of time before natural selection favoured those insects which could withstand a broad spectrum of chemical agents ${ }^{34-36}$. Faced with these problems, in 1973 WHO officials reluctantly transformed the Malaria Eradication Division into the Division of Malaria and other Parasitic Disease ${ }^{37,38}$.

\section{Agricultural expansion}

Against this background, it is ironic that commercial agriculture often expanded in precisely those regions recently cleared of malaria. As the danger of illness subsided, many landowners, stimulated by the high prices of such commodities as cotton, rice and tobacco, reduced their production of other crops and bought up more land ${ }^{39}$. The result of this development was both to augment the number of poor and landless rural workers and to concentrate agricultural resources in progressively fewer hands ${ }^{40}$. In 1960, for example, the wealthiest five per cent of India's non-urban population owned nearly one-third of its croplands; ten years later, making use of lavish credit facilities and development funds, they had actually increased their holdings by ten per cent

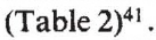

Naturally, such proprietors also claimed a disproportionate share of the country's agricultural income: between 1960 and 1970 , in fact, the richest 20 per cent of these people (like their counterparts in Pakistan and Bangladesh) collected nearly half of such earnings ${ }^{42}$. Similarly, in Central 
America, where cotton became king in the 1960 s, both land and credit remained almost completely inaccessible to most small growers. In El Salvador, one per cent of the rural population owned half of the country's land (including all properties over 50 hectares) and received 30 per cent of its income $\mathrm{in}^{4,44}$. As in India, such prosperity was achieved only at the expense of considerable inequity: one-third of the area's peasants possessed less than one hectare and one-quarter of them owned no land at all. Clearly, the expansion of commercial agriculture in these regions exacerbated such difficulties and created an entirely new kind of agroecosystem.

\section{Increased pesticide use}

In these circumstances, it is not surprising that the death rate from infectious and parasitic diseases in Central America has remained extremely high and that the incidence of malaria has generally increased - despite an impressive diminution in the late 1960 s and early $1970 \mathrm{~s}^{45}$. The relationship between fibre production and the recrudescence of malaria has been clearly established in a study by the United Nations Environmental Programme and the Instituto Centroamericano de Investigación y Tecnología Industrial (ICAITI) ${ }^{46}$. To combat cotton pests and to raise yields, planters in Guatemala, Nicaragua and El Salvador have not only expanded their acreage, but since 1970 they have also applied heavier concentrations of pesticides. Whereas a decade ago, fields were sprayed only eight or nine times each season, they must now be fumigated on as many as $\mathbf{5 0}$ occasions. Consequently, the amount of pesticide which enters the local ecosystem has expanded at an increasing rate.

In 1971, for example, farmers in El Salvador sprayed 58.4 kilos on each hectare of cotton; three years later, applications had reached $70.0 \mathrm{~kg}$ per hectare. As a result, DDT consumption in El Salvador increased threefold between 1970 and 1977 - from $555,200 \mathrm{~kg}$ to 1.6 million $\mathrm{kg}$. Similar circumstances prevailed in Nicaragua, where DDT imports rose from $29,000 \mathrm{~kg}$ in 1974 to $521,600 \mathrm{~kg}$ in 1976 .

Naturally, the importation of pesticides on this scale could be accomplished only as long as cotton revenues offset the rising cost of toxins. Fearful that unstable prices and soaring expenses might soon cut their earnings and anxious to maximize the returns on their investments, many growers have attempted to achieve total control of insect parasites - an obsession which has only enhanced their reliance on expensive chemicals. Correlating the use of DDT in El Salvador with renewed malaria transmission, it can be estimated that at current rates each kilo of insecticide added to the environment will generate 105 new cases of malaria $^{47-49}$.

Ironically, Anopheles resistance in India has developed even in areas where cotton is grown on relatively small plots of land or where food grains - primarily rice - still predominate. In Tamil Nadu, for example, most farmers (77.5 per cent) own less than one hectare; few possess more than two ${ }^{50}$. Even so, these men (and their counterparts in Maharashtra and Gujarat) produce nearly one-third of the country's cotton and an impressive share of its rice ${ }^{51,52}$. By 1968 , too, the incidence of malaria in this region had decreased to insignificance indeed, in Tamil Nadu, the disease was

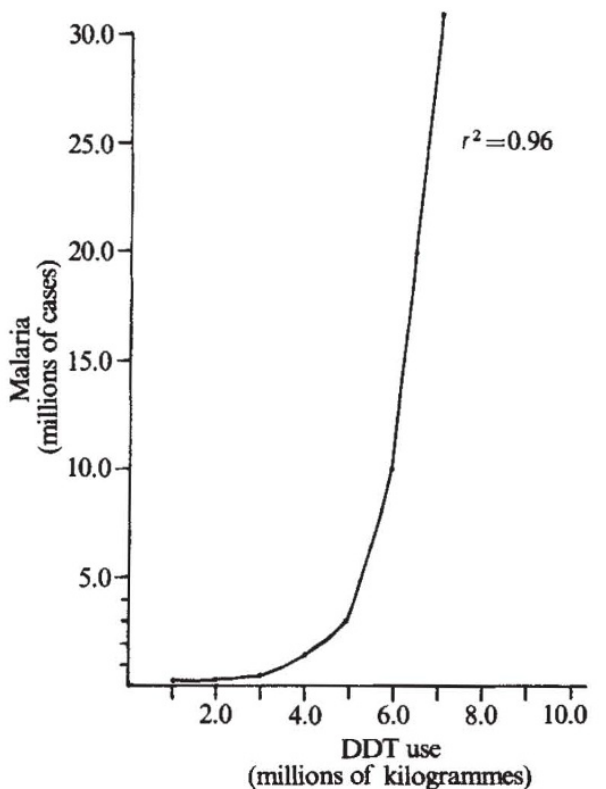

Fig.2 Relationship between DDT use and malaria incidence in India, 1969-77

largely confined to urban areas such as Madras ${ }^{53-56}$. Within a few years, however, public health officials throughout southern India reported that mosquitoes of both the Anopheles and Aedes subfamilies (the latter transmit yellow fever) had become resistant to a wide variety of chemicals including DDT, BHC, malathion (an organophosphate) and propoxur (a carbamate) $)^{57-61}$.

\section{Resistance to pesticides}

Indisputable evidence is not yet available but it appears that resistance began to occur with the introduction of green revolution technology - particularly of high-yielding varieties (HYV) of rice (Fig.1). According to entomologists at the Vector Control Research Centre in Pondicherry, "the major changes that have been taking place in the area are in the tremendous increase of acreage under cultivation, the near total replacement of organic manure by chemical fertilizers and the extensive use of insecticides for paddy and other crops" 62 . It should be noted that the new strains of rice have been adopted primarily by wealthy landowners and have proved to be especially susceptible to insect infestation ${ }^{63-66}$

Recent studies in Tamil Nadu indicate that families which own two hectares or more (7.2 per cent of the total number) alone possess the means to purchase HYV seeds, fertilizers and pesticides ${ }^{67-69}$. As Figs 2 and 3 suggest, such farmers have responded to increased infestation by applying heavy doses of DDT, BHC and dieldrin - a procedure which is closely related to the recent explosion of malaria in the region. Significantly, as these growers have switched from DDT to more sophisticated chemicals, traditional vectors have been replaced by rarer species which in turn show a diminished sensitivity to such poisons ${ }^{70}$. Little wonder, therefore, that as early as 1972 the Indian Journal of Public Health warned that "the most serious threat to public health .... is the uncontrolled use of pesticides for agronomic practice"'71.

\section{Deadly link}

There seems to be a three-stage relationship between the evolution of cotton agroecosystems and the spread of malaria. During the first stage, eradication programmes are more or less effective and often permit farmers to exploit previously infected areas. An example is to be found in eastern Paraguay, where landless peasants from so-called overpopulated regions have been encouraged to clear and colonize "uninhabited" jungle in which malaria is endemic ${ }^{72}$. The Paraguayan government has made great efforts to eliminate the Plasmodium parasite - as a stimulus to both immigration and productivity. Among its primary objectives, the production of cotton and tobacco (also a heavy user of pesticides) for export occupies a pre-eminent position. By 1978 , these two crops provided over 27 per cent of the country's foreign exchange. Having prepared vast expanses of virgin forest for commercial exploitation, however, peasants in many areas have begun to abandon their farms and to look for wage labour elsewhere. As their lands are consolidated into larger holdings, such areas will inevitably be treated with intensive applications of DDT or dieldrin. These lands will therefore probably come to resemble many parts of Central America (stage two), in which the high price of cotton appears to justify augmented doses of pesticides. Malaria transmission will be stimulated most markedly among migrant workers and impoverished peasants. Perhaps in anticipation, PAHO has already commissioned a study in Paraguay, The Impact of Malaria on Economic Development ${ }^{73}$, according to which seasonal increases in Plasmodium infection do not interfere with cotton or tobacco cultivation - although they may wreak havoc on food production. Finally, in places like India, Pakistan and Bangladesh (stage three), more and more DDT must be sprayed simply to maintain a fixed yield (Fig. 4). In this case, pesticide addiction and a full-fledged epidemic of malaria have entered their most destructive phase. 
So must countries such as India and El Salvador cease to grow cotton and highyielding food grains? Can foreign currency be obtained only at the expense of widespread malnutrition and disease? It is instructive to examine how such crops are produced in the United States. American farmers who started raising cotton with only small quantities of insecticides found that insect pests reappeared in their fields almost as soon as the fumigators departed ${ }^{74-78}$. Most often, they responded by applying stronger poisons with greater frequency until they were spraying every two or three days for five months ${ }^{79}$. The side effects had by then become apparent: cattle fodder had to be destroyed because it contained pesticide residues too high to be fed to animals while crops that had never suffered severe infestations were suddenly devastated by previously innocuous insects $^{80-84}$.

\section{Integrated pest management}

In response, entomologists developed what they call integrated pest management systems $\mathrm{s}^{85,86}$, the key to which lies in timing insecticide applications so that the crop is protected from predators only at the most vulnerable stages of its growth cycle. As it turns out, cotton buds destroyed by pests regrow throughout the plant's life, so that producers can afford to sustain a high level of insect damage before there is a need to apply pesticides. Simple precautionary measures may also lower their chemical costs: up to 75 per cent of the hibernating boll weevil population may be eliminated by the ploughing under of crop debris after harvest. Thus many growers west of the Mississippi now spray their fields only seven or eight times each season instead of 25 or 30 ; similar measures have been developed for raising corn, rice and many kinds of fruit ${ }^{87}$.

So why did WHO not urge cotton producing countries to employ integrated management systems that would not

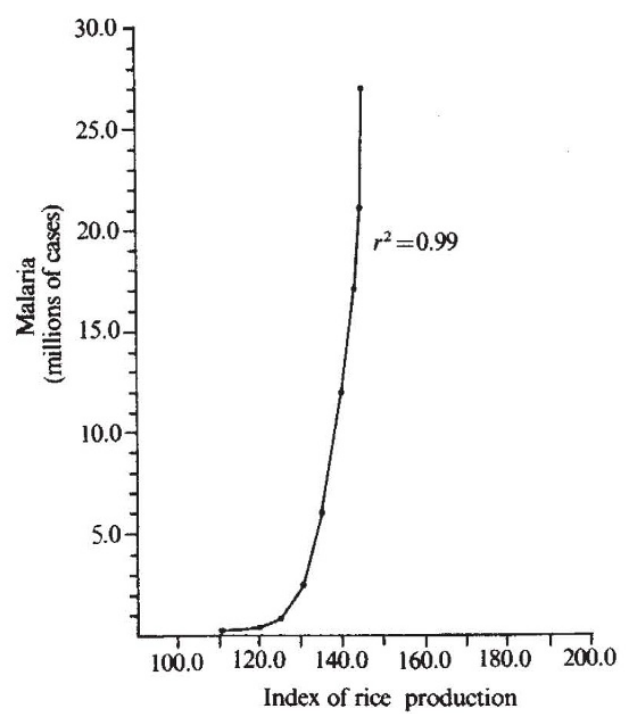

Fig.3 Relationship between rice production and malaria incidence in India, 1969-77 interfere with malaria eradication programmes? A possible answer may perhaps be found in the activities of another international agency, the Food and Agricultural Organization (FAO). Like WHO, FAO was established to provide technical advice and assistance to members of the United Nations. In the case of pesticides, which are manufactured and distributed by a few multinational corporations, FAO's advice might have played a critical role in reducing environmental contamination. Both farmers and extension agents in developing nations must normally rely on pesticide company salesmen for information about how to use agricultural chemicals - much as physicians in Western countries rely upon pharmaceutical companies for information about new drugs. Beginning in 1967 , therefore, FAO put together a small working group of experts on integrated pest management which published technical manuals and disseminated other information $^{88-94}$.

Three years later, it commissioned an American entomologist, Dr Louis Falcon, to develop an integrated system in Nicaragua, a system which achieved remarkable success within a few seasons. Similar programmes were subsequently undertaken in Mexico, Peru and Pakistan ${ }^{95}$. Then, in 1975, FAO delegates met in Rome to consider the question of pesticides in agriculture and public health. Although they recognized that integrated pest management offered a potential solution to many health problems, they recommended that FAO place its emphasis on teaching growers in developing nations how to make more "safe and efficient" use of pesticides ${ }^{96,97}$.

\section{Whys and wherefores}

Why did FAO choose this course of action, which in retrospect does not appear to have been guided by an accurate appreciation of the perils of pesticide addiction? It is important to examine how pesticide manufacturers have influenced the policies of international agencies. As public concern about the effects of toxins like DDT began to grow in the 1960 s, these corporations formed a trade association called GIFAP (Groupement International des Associations Nationales de Pesticides) which in turn worked directly with UN technicians through a FAO bureau known as the Industry Cooperative Programme (ICP). By the early 1970 s joint FAO-ICP regional seminars had been organized in many parts of the world to promote new and better ways of distributing agricultural pesticides. More important, high-level officials in WHO and FAO, who share the industry's views on many major issues, invited GIFAP to play an active part in agency "consultations" and other internal meetings ${ }^{98,99}$. In this way, for example, no fewer than 25 corporate representatives lent their expertise to the meeting in Rome

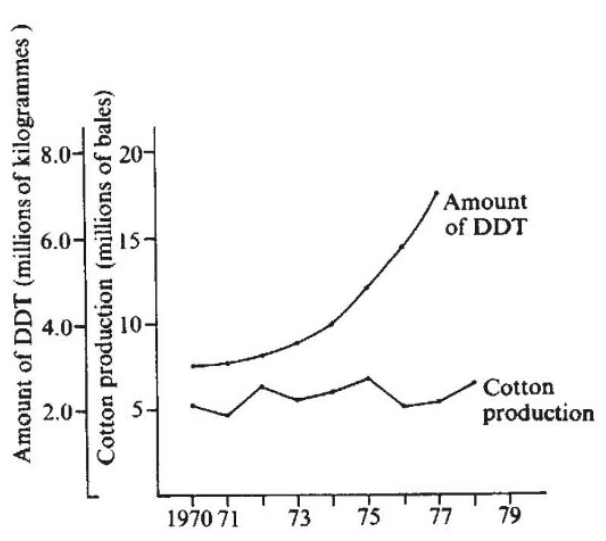

Fig.4 Cotton production and DDT use in India, 1970-78

on pesticides in agriculture and public health and served on subcommittees responsible for formulating UN policy. Not surprisingly, these subcommittees stressed the need to apply more pesticides in a more effective manner rather than to limit their use or replace them with alternative forms of pest control. And what is more curious, none of these deliberations included representatives of other international constituencies such as environmental groups, labour unions or farmers' organizations. Perhaps for these reasons, in June 1978, the current director general of FAO, Eduard Saoumi, finally expelled ICP from his agency ${ }^{100}$.

\section{The problem}

In 1976, WHO published a technical report entitled Resistance of Vectors and Reservoirs of Disease to Pesticides ${ }^{101}$. In this report, WHO's Expert Committee on Insecticides declared that "resistance is probably the biggest single obstacle in the struggle against vector-borne diseases and is mainly responsible for preventing successful malaria eradication in many countries . . . Evidence has also accumulated to show conclusively that resistance in many vectors has been caused as a side-effect of agricultural pesticide usage". Accepting this unhappy fate, the report concluded that "vector control was likely to depend on substantial, continued use of pesticides for at least a decade''. In these circumstances, it foresaw no alternative but to "encourage commercial firms to continue the search for pest control, especially compounds with a novel mode of action". And yet, as many specialists have pointed out, such compounds are unlikely to resolve this dilemma or to undo the damage which in-bred tolerance has already caused: detoxification appears to rely on physiological processes which are both irreversible and difficult to disrupt. In effect, thoughout southern India, the recrudescence of malaria now represents a social cost of growing high-yielding rice just as elsewhere in India and Cental America it represents a social cost of producing cotton. 
Recognizing such difficulties, in the same year WHO - joined by the World Bank and the United Nations Development Programme - established its Special Programme of Research and Training in Tropical Diseases (TDR) to coordinate efforts against six ancient scourges of mankind (malaria, schistosomiasis, the filariases, trypanosomiasis, leishmaniasis and leprosy) ${ }^{102}$. By June 1980, TDR had allocated over $\$ 2.8$ million to 38 separate projects concerned with problems of Anopheles resistance and Plasmodium transmission. Unfortunately, however, these projects tend to reflect WHO's conviction that progress in the field of malaria research depends almost uniquely on basic breakthroughs in such areas as biology, immunology and the invention of new drugs. So far, only 7.1 per cent of TDR's malaria funds support inquiries into nonchemical means of vector control ${ }^{103}$. Or as Peter Collins has written, the programme draws its models from "many of the ideas and techniques developed by biomedical research into the diseases of the indus-

1. Brown, A.W.A., Haworth, J. \& Zahar, A.R. J. med. Ent. 13, 1-25 (1976).

2. Dutta, H.M. \& Dutt, A.K. Soc. Sci. Med. 12, 69-8 (1978).

3. Gabaldon, A. in Vector Control and the Recrudescence of Vector-Borne Diseases, 23-24 (Pan American Health Organization, Washington DC, 1972).

4. Lepes, T. J. trop. Med. Hyg. 77, Suppl., 47-53 (1974).

5. WHO tech. Rep. Ser. No. 537 (World Health Organization, Geneva, 1974)

6. Harrison, G. Mosquitoes, Malaria and Man: A Histor of the Hostilities Since 1880 (Dutton, New York, 1978).

World Health Statistics Annual (World Health Organization, Geneva, yearly updates).

8. Ariaratnam, V. \& Georghiou, G.P. Bull. Wld Hlth Org. $51,655-659$ (1974)

9. Brader, L. A Rev. Ent. 24, 225-254 (1979)

10. Breeland, S.G. et al. Bull. Wld Hlth Org. 43, 627-63 (1970).

11. Brown, A.W.A. in Vector Control and the Recrudescence of Vector-Borne Diseases, 59-63 (Pan American Health Organization, Washington DC, 1972).

12. Busvine, J.R. Nature 273, 604-607 (1978).

13. Hadjinicolaou, J. \& Betzios, B. Bull. Wld Hlth Org. 48 699-703 (1973).

14. Jeffery, G.M. Am. J. trop. Med. Hyg. 25, 361-271 (1976).

15. WHO tech. Rep. Ser. No. 585 (1976).

16. Harrison, G. Mosquitoes, Malaria and Man: A History of the Hostilities Since 1880 (Dutton, New York, 1978).

17. McIntire, G. Environment 14, 14-29 (1972).

18. PAHO scient. Publ. No. 238 (1972).

19. Garcia, R. Environment 14, 2-9 (1972).

19. Garcia, R. Environment 14, 2-9 (19

21. Mason, J. Am. J. trop. Med. Hyg. 24, 581-585 (1975)

22. Rachou, R.G., Schinazi, L.A. \& Moura Lima, M. Rev bras. Malar. Doenç. trop. 25, 1-293 (1973)

23. Roy, R.G. et al, Ind. J. med. Res. 69, 53-59 (1979).

24. Roy, R.G. et al. Ind. J. med. Sci. 30, 313-316 (1976).

25. Harrison, G. Mosquitoes, Malaria and Man: A Histor of the Hostilities Since 1880(Dutton, New York, 1978).

26. WHO tec. Rep. Ser. No. 537 (1974)

27. Davidson, G. \& Zahar, A.R. Bull. Wld Hlth Org. 49, 475-483 (1973)

28. Brown, A.W.A., Haworth, J. \& Zahar, A.R. J. med Ent 13, 1-25 (1976)

29. García Martín, G. \& Nájera-Morrondo, J. Boln Of. Sanit. Panam. (Engl. edn) 6, 15-23 (1972).

30. Rachou, R.G., Schinazi, L.A. \& Mourna Lima, M. Rev. bras. Malar. Doenç. trop. 25, 1-293 (1973).

31. de Zulueta, J. \& Garrett-Jones, C. A m. J. trop. Med. Hyg. 14, 63-77 (1965).

32. Mojamdar, V.G. Ind. J. publ. Hith 29, 107-114 (1975)

33. Ghatak, S. \& Turner, R.K. Food Policy 3, 136-46 (1978)

34. Benson, R.L. BioScience 21, 1160-1165 (1971).

35. Georghiou, G.P. A. Rev. Ecol. Syst. 3, 133-168 (1972).

36. Plapp, F.W. A. Rev. Ent. 21, 179-197 (1976).

37. Harrison, G. Mosquitoes, Malaria and Man: A History of the Hostilities Since 1880 (Dutton, New York: 1978).

38. WHO Chron. 32, 226-230 (1978)

39. Agricultural Land Settlement (World Bank, Washington DC, 1978)

40. George, S. How the Other Half Dies (Allanheld, trialised, affluent world" 104 .

\section{A solution?}

Must poor countries inevitably choose between more productive forms of agriculture and the uncontrollable spread of parasitic disease, between the irreconcilable claims of "food versus health", as several writers have recently proposed? The evidence, based on a common pattern of social and epidemiological factors appears to suggest another conclusion. In almost every major case of malaria resurgence, large landowners overuse pesticides on crops like cotton and tobacco which make no substantial contribution to the subsistence requirements of the rural poor. Instead, income from such ventures is generally channelled into luxury consumption at home or speculative investments abroad; only in rare instances does it serve to finance the production of basic foodstuffs or capital equipment.

Even more distressing, much the same situation now prevails in India's main ricegrowing regions, where the technology of

New York, 1977)

41. Singh, I. World Bank Staff Working Pap. No. 32 (1979).

42. Ojha, P.H. \& Bhatt, V.V. Sankhya 36, 163-166 (1974). 43. Dorner, P. \& Quirós, R. J. Latin Am. Stud. 5, 217-232 (1973).

44. Informe General Sobre el Desarrollo Agropecuario Rural de El Salvador (World Bank/Interamerican Development Bank, Washington DC, 1976)

45. PAHO scient, Publ. No. 364 (1978)

46. An Environmental and Economic Study of the Consequences of Pesticide Use in Central America Cotton Production (Instituto Centroamericano de Investigación y Tecnología Industrial, Guatemala, 1977)

47. FAO Prod Yb. 31 (1977).

48. FAO Trade Yb. 31 (1977)

49. World Health Statistics A nnual (World Health Organization, Geneva, yearly updates).

50. Mencher, J. Agriculture and Social Structure in Tamil Nadu (Carolina Academic, Durham, Nort Carolina, 1978).

51. Statistical Abstract, India, 1977 (Ministry of Planning, Government of India, Delhi, 1978).

52. Statistical Outline of India (Tata Services Ltd, Bombay, 1978).

53. Das, P.K., Reuben, R. \& Batra, C.P. Ind. J. med. Res 69, 403-411 (1979)

54. Dutta, H.M., Dutt, A.K. \& Vishnukumari, G. Soc. Sci. Med. 13, 191-194 (1979).

55. Rajagopalan, P.K., Chandrahas, R.K. \& Paniker, K.N Ind. J. med. Res. 69, 589-597 (1979).

56. Roy, R.G. et al. Ind. J. med. Res. 67, 947-952 (1978).

57. Kaul, H.N. et al. Ind. J med. Res, 64, 1760-1768 (1976).

58. Mojamdar, V.G. Ind. J. publ. Hlth 29, 107-114 (1975).

59. Rajagopal, R. Ind. J. med. Res. 66, 27-28 (1979).

60. Roy, R.G. et al. Ind. J. med. Res. 68, 744-746 (1978).

61. Pant, C. \& Gratz, N. Outlook Agric. 10, 111-115 (1979).

62. Rajagopalan, P.K., Chandrahas, R.K. \& Paniker, K.N Ind. J. med. Res. 69, 589.597 (1979).

63. Apple, J.L. BioScience 22, 461-463 (1972).

64. Hargrove, T.R. \& Cabanilla, V.L. BioScience 29, 731.735 (1979).

65. Smith, R.F. Bull. ent. Soc. Am. 18, 7-14 (1972)

66. Chakravarti, A. Ann. Ass. Am. Geogr. 63, 319-330 (1973).

67. Mencher, J. Agriculture and Social Structure in Tamil Nadu (Carolina Academic, Durham, North Carolina, 1978).

68. Harriss, J. Devl Change 11, 33-64 (1980).

69. Chakravarti, A. Ann. Ass. Am Geogr 63, 319-330 (1973).

70. Das, P.K., Reuben, R. \& Batra, C.P. Ind.J. med. Res. 69, 403-411 (1979).

71. Ind. J. publ. Hlth 16, 105-106 (1972).

72. Paraguay: Regional Development in Eastern Paraguay World Bank, Washington DC, 1978).

73. Conly, G.N. PAHO scient. Publ. No. 297 (1975).

74. Bottrell, D.G. \& Adkisson, P.L. A. Rev. Ent. 22, 451.481 (1977)

75. Cross, W.H. A. Rev. Ent. 18, 17-46 (1973)

76. Glass, E.H. \& Thurston, H.D. BioScience 28, 109-115 (1978).

77. Irving, G.W. Jr Science 168, 1419-1424 (1970).

78. Philogene, B.J.R. BioScience 22, $715-717$ (1972).
HYV rice cultivation has been available principally to wealthy farmers who sell their grain at premium prices. Many specialists now feel that the green revolution in such regions has not significantly improved the lot of most peasants and smallholders ${ }^{105}$

Acknowledging this fact, institutions like the International Rice Research Institute and the International Maize and Wheat Improvement Center have begun to reevaluate the advantages both of traditional plant varieties and of native cultivation techniques. Perhaps the problem of malaria resurgence is amenable to similar solutions, not by means of technological innovation alone, but also by showing a proper respect for the social and environmental conditions which make resurgence unavoidable. And while more equitable answers are found to the question of poverty and landlessness, surely it makes sense (as FAO's own panel of experts has once again reaffirmed) to employ an integrated system of pest management on such crops as rice and cotton.

79. van den Bosch, R. The Pesticide Conspiracy (Anchor/ Doubleday, New York, 1980)

80. Aldrich, S.A. BioScience 22, $90-95$ (1972).

81. Luck, R.F., van den Bosch, R. \& Garcia, R. BioScience 27, 606-611 (1977).

82. Weir, D. \& Shapiro, M. Circle of Poison: Pesticides and People in a Hungry World (Institute for Food and Development Policy, San Francisco, 1980).

83. Pimentel, D. et al. BioScience 28, 772-784 (1978)

84. van den Bosch, R. Environment 14, 18-31 (1972)

85. Bottrell, D.G. \& Adkisson, P.L. A. Rev. Ent. 22 451-481 (1977).

86. Ruesink, W.G. A. Rev. Ent. 21, $27-44$ (1978)

87. Kiritani, K. A. Rev. Ent. 24, 279-312 (1979)

88. Integrated Pest Control (Food and Agricultural Organisation, Rome, 1977).

89. Report on FAO Expert Consultation on Pesticides and the Environment (AGP: 1977/M/7, Food and Agricultural Organisation, Rome, 1977).

90. Report of the Fifth Session of the FAO Panel of Experts on Integrated Pest Control (AGP: 1975/M/2, Food and Agricultural Organisation, Rome, 1975).

91. The Development and Application of Integrated Pest Control in Agriculture: Formulation of a Cooperative Global Programme (AGP: 1974/M/8, Food and Agricultural Organisation/United Nations Environmental cultural Organisation/Unit

92. Impact Monitoring of Agricultural Pesticides (AGP: 1976/M/4, Food and Agricultural Organisation/ United Nations Environmental Programme, 1976).

93. Falcon, L.A. \& Smith, R.F. Guidelines for Integrated Control of Cotton Insect Pests (FAO/AGPP: MISC/8, Food and Agricultural Organisation, Rome, 1973).

94. Integrated Pest Control (AGP: 1979/M/1, Food and Agricultural Organisation/United Nations Environmental Programme, Rome, 1979)

95. Ling, L.L. A. Rev. Ent. 19, 177-196 (1974).

96. Report of the Ad Hoc Government Consultation on Pesticides in Agriculture and Public Health (AGP. 1975/M/3, Food and Agricultural Organisation. Rome, 1975).

97. Impact Monitoring of Residues from the Use of Agricultural Pesticides in Developing Countries (AGPP $\mathrm{MISC} / 22$, Food and Agricultural Organisation, Rome, 1975).

98. Report of the Ad Hoc Government Consultation on Pesticides in Agriculture and Public Health (AGP: 1975/M/3, Food and Agricultural Organisation, Rome, 1975).

99. George, S. How the Other Half Dies (Allanheld, New York, 1977).

100. Tayłor, W. Multinational Monitor 2, 24-26 (1980).

101. WHO tech. Rep. Ser. No.585. (1976)

102. Action Against Tropical Diseases (United Nations Development Programme/World Bank/World Health Organisation Special Programme for Research \& Training in Tropical Diseases, Geneva, 1978).

103. Fourth Annual Report, I July 1979-30 June 1980 (UN Development Programme/World Bank/World Health Organisation Special Programme for Research \& Training in Tropical Diseases, Geneva, 1980).

104. Collins, P. Nature 269, 550-551 (1977).

105. Pearse, A. Seeds of Plenty, Seeds of Want (Clarendon/ Oxford University Press, Oxford, 1980). 